\title{
Penggunaan Pupuk Organik Cair Tauge pada Budidaya Tanaman Kailan (brassica oleraceae var. Acephala) Sistem Vertikultur
}

\author{
Nawawi, Siti M. Sholihah, Luluk Syahr Banu \\ Program Studi Agroteknologi Fakultas Pertanian Universitas Pertanian Jakarta \\ Email : nawi14n@gmail.com
}

\begin{abstract}
ABSTRAK
Tanaman Kailan (Brassica oleraceae var. acephala) merupakan jenis sayuran Famili kubiskubisan (Brassicaceae) yang berasal dari negeri China. Kailan termasuk sayuran semusim dan berumur pendek sekitar 40 hari sampai 50 hari setelah bibit ditanam. Umumnya budidaya tanaman kailan menggunaan pupuk an organik namun penggunaan pupuk an organik juga memiliki kekurangan, yaitu bersifat sintetis (kimia) dan harga nutrisi $A B$ mix yang cukup mahal dan dapat menyebabkan kepadatan pada tanah itu sendiri oleh karena perlu adanya alternatif upaya budidaya tanaman sayuran secara organik salah satunya dengan memanfaatkan tauge yang sudah tidak layak untuk dikonsumsi menjadi pupuk organik cair (POC) tauge. Tujuan penelitian ini adalah mengetahui pengaruh pemberian $P O C$ tauge terhadap pertumbuhan Tanaman Kailan serta konsentrasi POC Tauge yang memberikan pertumbuhan dan hasil tanaman Kailan terbaik. Penelitian menggunakan Rancangan Acak Kelompok terdiri dari 5 perlakuan dan 4 ulangan sehingga berjumlah 20 satuan percobaan, perlakuan terdiri dari 5 level yaitu PO $(0 \mathrm{ml}$ POC tauge/liter air) tanpa pemberian POC Tauge, P1 (20 ml POC tauge/liter air), P2 (40 ml POC tauge/liter air, P3 (60 ml POC tauge/liter air), dan P4 (80 ml POC tauge/liter air). Hasil penelitian menunjukan konsentrasi $\mathrm{POC}$ tauge tidak berpengaruh terhadap tinggi tanaman, jumlah daun dan panjang akar, tetapi berpengaruh terhadap bobot basah tanaman kailan. Konsentrasi POC 60 $\mathrm{ml} /$ liter memberikan hasil pertumbuhan terbaik yaitu tinggi tanaman $27,5 \mathrm{~cm}$; jumlah daun 12,75 helai; panjang akar $11.25 \mathrm{~cm}$; bobot basah $110,13 \mathrm{gr}$.
\end{abstract}

Kata kunci : Pupuk Organik Cair, Tauge, Tanaman Kailan, Hasil, Sistem Vertikultur

\section{ABSTRACT}

Kailan plant (Brassica oleraceae var. acephala) or kale is a type of vegetable from the cabbage family (Brassicaceae) originating from China. Kailan is an annual vegetable and is shortlived about 40-50 days after the seeds are planted. In general, kailan cultivation uses inorganic fertilizers, but the use of inorganic fertilizers also has drawbacks, namely they are synthetic (chemical) and the price of $A B$ mix nutrients is quite expensive and can cause density in the soil itself because of the need for alternative efforts to cultivate vegetable crops organically. one of them is by using bean sprouts that are no longer suitable for consumption into liquid organic fertilizer (POC) bean sprouts. The aims of this study were (1) to determine the effect of POC bean sprouts on the growth of Kailan plants, (2) to determine the concentration of POC bean sprouts that gave the best growth and yield of Kailan plants. This research method used a Randomized Block Design (RAK), consisting of 5 treatments and 4 replications so that there were 20 experimental units, the treatment consisted of 5 levels consisting of PO $(0 \mathrm{ml} \mathrm{POC}$ bean sprouts/liter of water) without POC bean sprouts, P1 $(20 \mathrm{ml})$. POC bean sprouts/liter water), P2 (40 $\mathrm{ml} \mathrm{POC} \mathrm{bean} \mathrm{sprouts/liter} \mathrm{water,} \mathrm{P3} \mathrm{(60} \mathrm{ml} \mathrm{POC} \mathrm{bean} \mathrm{sprouts/liter} \mathrm{water),} \mathrm{and} \mathrm{P4}(80 \mathrm{ml}$ POC bean sprouts/liter water). The results showed that the POC concentration of bean sprouts had no effect on plant height, number of leaves and root length, but did affect the wet weight of kailan plants. POC concentration of $60 \mathrm{ml} /$ liter gave the best growth results, namely plant height $27.5 \mathrm{~cm}$, number of leaves 12.75 strands, root length $11.25 \mathrm{~cm}$ and wet weight $110.13 \mathrm{~g}$. 
Key words : POC Bean Sprouts, Kailan Plant, Product, Verticulture System

\section{PENDAHULUAN}

Tanaman Kailan merupakan jenis sayuran Famili kubis-kubisan (Brassicaceae) yang berasal dari negeri China. Kailan termasuk sayuran semusim dan berumur pendek sekitar 40-50 hari setelah bibit ditanam. Jika kailan dipanen terlalu tua maka daun dan batangnya telah keras sehingga sudah tidak enak dikonsumsi. Kailan yang dipanen saat muda disebut baby kailan. Baby Kailan lebih diminati karena rasanya lebih enak dan renyah. Selain sebagai bahan pangan, Kailan juga dimanfaatkan untuk terapi berbagai macam penyakit karena mengandung karotenoid yang memiliki aktivitas anti kanker. Nilai ekonomi Kailan tinggi karena pemasarannya untuk kalangan menengah ke atas, terutama banyak tersaji di restoran bertaraf internasional seperti restoran Cina, Jepang, Amerika, Eropa, serta hotel berbintang. Hal ini menuntut Kailan yang diproduksi harus berkualitas tinggi [12].

\section{Lahan pertanian yang semakin} sempit menyababkan kegiatan budidaya tanaman menjadi sulit dilakukan terutama untuk lahan pertanaman di perkotaan. Solusi yang tepat untuk mengatasi penyempitan lahan pertanian dan terbatasnya lahan dengan bercocok tanam secara vertikultur.Budidaya tanaman dengan cara vertikultur ini mudah dilakukan oleh siapa saja dan tidak memerlukan suatu keahliankhusus. Teknik budidaya secara vertikultur diharapkan dapat membantu permasalahan terbatasnya lahan bagi mereka yang memiliki mata pencaharian dari kegiatan bercocok tanam atau bagi mereka yang menekuninya sebagai hobi. Peluang usaha dibidang pertanian terkait dengan vertikultur mempunyai potensi untuk berkembang pesat [1].

Pupuk merupakan suatu nutrisi yang dibutuhkan tanaman untuk pertumbuhan dan perkembangan. Pupuk secara umum dibedakan menjadi dua yaitu pupuk anorganik dan pupuk organik. Pupuk anorganik merupakan pupuk yang terbuat dari bahan-bahan kimia aktif seperti pestisida yang diproduksi oleh pabrik-pabrik kimia yang beredar dipasaran. Sedangkan pupuk organik yaitu pupuk yang terbuat dari pelapukan organisme tumbuhan atau hewan. Terdapat dua macam pupuk organik yaitu pupuk organik padat dan organik cair. Pupuk organik padat merupakan pupuk organik yang berasal dari sisa tanaman, kotoran hewan, dan kotoran manusia yang berbentuk padat sedangkan pupuk organik cair merupakan larutan yang berasal dari pembusukan bahan-bahan organik. Kelebihan pupuk organik cair adalah mampu memberikan hara bagi tanaman tanpa merusak unsur hara di dalam tanah dan lebih mudah diserap oleh tanaman [4].

Pupuk organik adalah pupuk yang 
sebagian besar tersusun dari material makhluk hidup seperti pelapukan sisa-sisa tanaman, hewan dan manusia. Berdasarkan bentuknya, pupuk organik dibedakan menjadi dua bagian yaitu pupuk organik padat dan pupuk organik cair. Pupuk organik cair yaitu jenis pupuk organik yang berupa cairan [9].

Pupuk organik cair adalah larutan yang berisi satu atau lebih pembawa unsur hara yang dibutuhkan oleh tanaman. Pupuk organik cair yaitu pupuk yang berupa larutan dari hasil pembusukan bahan-bahan organik yang berasal dari sisa tanaman, kotoran hewan, dan manusia yang kandungan unsur haranya lebih dari satu unsur. Kelebihan pupuk cair adalah mampu memberikan hara bagi tanaman tanpa merusak unsur hara dalam tanah dan lebih mudah diserap tanaman [4].

Salah satu bahan organik yang berpotensi untuk dapat dijadikan pupuk organik cair yang lebih berkualitas adalah tauge. Hasil fermentasi tauge selain mengandung unsur hara makro dan hara mikro, juga mengandung fitohormon [5]. Fitohormon adalah senyawa organik yang bukan hara, namun dalam jumlah sedikit dapat mendukung proses pertumbuhan tanaman. Tiga jenis fitohormon tersebut adalah auksin, giberelin dan sitokinin [14]. Masing-masing jenis fitohormon tersebut memiliki fungsi yang berbeda dalam memacu pertumbuhan tanaman, bahkan fungsinya ada yang bersifat sinergis satu dengan yang lainnya.

Pemberian POC tauge dengan dosis $36 \mathrm{ml} /$ ldapat menghasilkan71.67 buah cabe dan berat cabe sebesar 229,33gr [8]. Pemberian ekstrak tauge dengan dosis penggunaan 20-30 $\mathrm{ml} / \mathrm{l}$ air dapat meningkatkan pertumbuhan tanaman Caisim [12]. Ekstrak tauge dapat menyebabkan kandungan fosfor pada pupuk organik cair tinggi karena didalam ekstrak tauge terdapat kandungan makronutrien seperti fosfor, magnesium vitamin $A$, besi dan kalsium. Hal ini dibuktikan dalam penelitian [2], bahwa dalam $100 \mathrm{~g}$ tauge terdapat $\mathrm{P}$ sebesar $340 \mathrm{mg}, \mathrm{Fe}$ 7,7 mg, Ca $125 \mathrm{mg}$, karbohidrat 62,9mg, Na 6 mg, vitamin A $157 \mathrm{IU}$, vitamin B1 0,64 mg, vitamin C $6 \mathrm{mg}$ dan air $10 \mathrm{~g}$. Unsur hara tersebut akan membantu mempercepat pertumbuhan tanaman [7]

\section{METODE}

\section{Waktu dan Tempat}

Penelitian dilaksanakan di Kantor Balai Penyuluhan Pertanian (BPP) Ujung Menteng Kecamatan Cakung pada Februari sampai dengan September 2021.

\section{Bahan dan Alat}

Bahan yang digunakan dalam penelitian ini adalah benih Kailan Varietas winsa, tanah, pupuk kandang, sekam, POC Tauge. Alat yang digunakan dalam penelitian 
adalah instalasi rak vertikultur, pot Ukuran $35 \mathrm{~cm}$, gelas ukur, sprayer, timbangan digital, mistar, penyaring, pisau, kertas millimeter, glass objek, isolasi, dan kamera.

\section{Rancangan Penelitian}

Penelitian menggunakan Rancangan Acak Kelompok terdiri dari 5 perlakuan dan 4 ulangan sehingga berjumlah 20 satuan percobaan, perlakuan terdiri dari 5 level yaitu PO (0 ml POC tauge/liter air) tanpa pemberian POC tauge, P1 $(20 \mathrm{ml}$ POC tauge/liter air), P2 (40 ml POC tauge/liter air, P3 (60 ml POC tauge/liter air), dan P4 (80 $\mathrm{ml} \mathrm{POC} \mathrm{tauge/liter} \mathrm{air).}$

\section{Prosedur Penelitian}

\section{Pembuatan POC Tauge}

Penelitian ini dilakukan sebagai upaya mengolah tauge menjadi pupuk organik cair berfitohormon melalui proses fermentasi. Bahan yang digunakan dalam penelitian ini, terdiri dari tauge yang berasal dari kacang hijau, Effective Microorganism 4 (EM4), gula merah, telur dan air Kelapa . Alat yang digunakan dalam percobaan ini terdiri dari: blender dan jerigen ukuran 25 liter.

\section{Persiapan Rak vertikultur}

Persiapan pembuatan rak vertikultur dengan 4 tingkat sebanyak 1 buah di buat setelah penyemaian dan ketika tanaman kalian sudah siap pindah ke pot rak vertikultur sudah siap.

\section{Penyiapan Benih dan Pembibitan}

Persemaian benih dilakukan selama 2 minggu menggunakan tray semai berukuran $540 \mathrm{~mm} \times 280 \mathrm{~mm}$ dengan jumlah lubang 200 lubang dan ukuran tiap lubangnya 23/10 mm x $43 \mathrm{~mm}$. Tray semai diisi dengan media tanam tanah + arang sekam perbandingan 1:1. Dalam satu lubang tray semai, diisi 1-2 benih kailan.

\section{Pengisian Media Tanam di Pot}

Pengisian tanah dilakukan dengan memasukkan tanah, pupuk kandang dan sekam ke pot berukuran $35 \mathrm{~cm} \times 35 \mathrm{~cm}$ dengan perbandingan media tanam 1:1:1 setelah media dicampur mengan merata, dimasukan ke dalam pot setinggi $1 / 2$ pot dan setelah tanaman cukup besar ditambahkan lagi media tanam tersebut sampai penuh dengan tujuan agar tanaman berdiri tegak.

\section{Penanaman}

Penanaman dilakukan 2 minggu setelah persemaian dengan cara memindahkan benih pada tray semai ke pot besar berisi media tanam yang telah disiapkan, dengan lubang tanam $\pm 5 \mathrm{~cm}$. Penanaman bibit ini harus dilakukan dengan hati-hati agar tanaman tidak rusak dan bibit tanaman yang dipilih adalah bibit yang pertumbuhannya baik, dan seragam.

\section{Pemeliharaan}

\section{Pemupukan}


Pemberian pupuk organik cair Tauge dilakukan 6 kali yaitu pada umur 14 HST, 21 HST, 28 Hst, 35 Hst, 42 Hst dan 49 Hst per plot dengan cara menyiramkan pupuk organik cair Tauge ke tanah di pot, sesuai dengan perlakuan yang telah ditentukan yakni P0: Tanpa perlakuan (kontrol), P1: 20 $\mathrm{ml} /$ liter air, P2: $40 \mathrm{ml} /$ liter air, P3: $60 \mathrm{ml} /$ liter air dan P4: $80 \mathrm{ml} /$ liter air. Pemberian ini dilakukan pagi hari saat sinar matahari tidak terlalu terik, karena jika tidak proses penguapan akan terjadi.

\section{Penyiraman}

Penyiraman dapat dilakukan dengan menggunakan gembor, agar penyiraman merata dan dengan hari hati agar tanaman tidak patah atau rusak.

\section{Pengendalian Hama dan Penyakit Tanaman}

Pengendalian hama dilakukan
secara manual yaitu dengan mengutip
langsung hama yang terdapat pada tanaman kailan dengan menggunakan tangan dilakukan secara manual atau Selain itu, penggunaan pestisida hanya pada saat diperlukan saja misalnya ketika tanaman kailan diserang ulat grayak (Spodoptera litura) atau terkena penyakit busuk lunak (Erwinia carotovora) atau menggunakan pertisida Nabati.

\section{Pemanenan}

Tanaman kailan memiliki kriteria panen yakni dipanen pada saat tanaman berumur 45-50 hari setelah tanam sedang tanaman kailan biasa berkisar \pm 60 hari setelah tanam, warna daun hijau segar, tinggi batang berkisar 20-30 cm serta bentuk batang tebal, tegak, dan sehat. Pemanenan dilakukan dengan cara memotong pangkal batang yang berada diatas tanah dengan pisau tajam dan bersih. Apabila daun terbawah sudah mulai menguning maka tannaman harus secepatnya dipanen. Hal tersebut menandakan tanaman mulai memasuki fase generatif atau segera akan berbunga. Selain itu dapat dilihat dari daundaun mudanya berukuran besar.

\section{Variabel Penelitian dan Analisa Data}

Parameter pengamatan meliputi tinggi tanaman, jumlah daun, panjang akar, dan bobot basah tanaman kailan. Data yang diperoleh kemudian ditabulasikan dan dianalisis dengan menggunakan analisis sidik ragam atau Uji " $F$ " (Analysis of Varians) pada tingkat signifikan $5 \%$ Apabila terdapat perbedaan di antara perlakuan dilanjutkan dengan uji BNT.

\section{HASIL DAN PEMBAHASAN}

\section{Tinggi Tanaman}

Tinggi tanaman Kailan diukur sebanyak 6 kali yaitu pada umur 14 Hst, 21 Hst, 28 Hst, 35 Hst, 42 Hst, dan 49 Hst. Berdasarkan analisis sidik ragam menunjukan bahwa perlakuan konsentrasi 
Jurnal IImiah Respati

POC tauge tidak berpengaruh nyata umur pengamatan. Rata-rata tinggi terhadap tinggi tanaman kalian pada semua tanaman kalian dapat dilihat pada Tabel 2.

Tabel 2. Pengaruh Perlakuan terhadap Tinggi Tanaman Kailan

\begin{tabular}{lcccccc}
\hline \multirow{2}{*}{ Perlakuan } & \multicolumn{5}{c}{ Rata-rata Tinggi Tanaman $(\mathrm{Cm})$} \\
\cline { 2 - 7 } & $14 \mathrm{Hst}$ & $21 \mathrm{Hst}$ & $28 \mathrm{Hst}$ & $35 \mathrm{Hst}$ & $42 \mathrm{Hst}$ & $49 \mathrm{Hst}$ \\
\hline P0 (0 ml/Itr air) & $5.88 \mathrm{a}$ & $8.25 \mathrm{a}$ & $11.50 \mathrm{a}$ & $13.63 \mathrm{a}$ & $18.19 \mathrm{a}$ & $25.63 \mathrm{a}$ \\
P1 (20 //Itr air) & $6.00 \mathrm{a}$ & $8.63 \mathrm{a}$ & $11.50 \mathrm{a}$ & $13.88 \mathrm{a}$ & $18.25 \mathrm{a}$ & $24.25 \mathrm{a}$ \\
P2 (40 ml/Itr air) & $6.00 \mathrm{a}$ & $8.38 \mathrm{a}$ & $11.50 \mathrm{a}$ & $13.63 \mathrm{a}$ & $19.50 \mathrm{a}$ & $26.88 \mathrm{a}$ \\
P3 (60 ml//tr air) & $6.38 \mathrm{a}$ & $9.13 \mathrm{a}$ & $12.88 \mathrm{a}$ & $14.75 \mathrm{a}$ & $20.19 \mathrm{a}$ & $27.50 \mathrm{a}$ \\
P4 (80 ml/Itr air) & $5.88 \mathrm{a}$ & $9.38 \mathrm{a}$ & $12.00 \mathrm{a}$ & $14.00 \mathrm{a}$ & $17.88 \mathrm{a}$ & $26.50 \mathrm{a}$
\end{tabular}

Keterangan : Angka rata-rata yang diikuti oleh huruf yang sama tidak berbeda nyata menurut Uji BNT taraf nyata 5\%

Tabel 2 menunjukkan tinggi tanaman kalian tidak berbeda pada berbagai konsentrasi POC tauge. Hal ini disebabkan tanaman masih menggunakan unsur-unsur hara yang berada dalam media tanam pada pertumbuhan awalnya dan pemberian POC tauge pada tanaman kalian belum memberikan pengaruh. Pemberian pupuk yang mengandung Nitrogen mampu mensuplai unsur hara untuk pertumbuhan awal tanaman [3]. Unsur Nitrogen lebih banyak diperlukan untuk pembentukan zat hijau daun atau klorofil, selain itu nitrogen juga digunakan untuk pertumbuhan, terutama pada fase vegetatif untuk pertumbuhan batang, cabang dan daun [9].
Kekurangan unsur N menyebabkan pertumbuhan kerdil, daun menguning dan pertumbuhan akar terbatas sedangkan kelebihan $\mathrm{N}$ menyebabkan pertumbuhan vegetatif memanjang dan mudah rebah [6].

\section{Jumlah Daun}

Jumlah daun tanaman Kailan diukur sebanyak 6 kali yaitu pada umur 14 Hst, 21 Hst, 28 Hst, 35 Hst, 42 Hst, dan 49 Hst. Berdasarkan analisis sidik ragam menunjukan bahwa perlakuan konsentrasi POC tauge tidak berpengaruh nyata terhadap jumlah kalian pada semua umur pengamatan. Rata tinggi tanaman kalian dapat dilihat pada Tabel 3. 
Jurnal IImiah Respati

Tabel 3. Pengaruh Perlakuan Terhadap Jumlah daun Tanaman Kailan

\begin{tabular}{lcccccc}
\hline \multirow{2}{*}{ Perlakuan } & \multicolumn{5}{c}{ Rata-rata Jumlah Daun (Helai) } \\
\cline { 2 - 6 } & $14 \mathrm{Hst}$ & $21 \mathrm{Hst}$ & $28 \mathrm{Hst}$ & $35 \mathrm{Hst}$ & $42 \mathrm{Hst}$ & $49 \mathrm{Hst}$ \\
\hline P0 (0 ml/Itr air) & $4.38 \mathrm{a}$ & $5.50 \mathrm{a}$ & $7.13 \mathrm{a}$ & $8.13 \mathrm{a}$ & $9.63 \mathrm{a}$ & $10.75 \mathrm{a}$ \\
P1 (20 I/Itr air) & $4.88 \mathrm{a}$ & $6.00 \mathrm{a}$ & $7.13 \mathrm{a}$ & $8.50 \mathrm{a}$ & $10.13 \mathrm{a}$ & $10.75 \mathrm{a}$ \\
P2 (40 ml/Itr air) & $4.75 \mathrm{a}$ & $5.88 \mathrm{a}$ & $7.63 \mathrm{a}$ & $9.00 \mathrm{a}$ & $10.63 \mathrm{a}$ & $11.25 \mathrm{a}$ \\
P3 (60 ml/Itr air) & $5.00 \mathrm{a}$ & $5.75 \mathrm{a}$ & $7.38 \mathrm{a}$ & $8.88 \mathrm{a}$ & $11.38 \mathrm{a}$ & $12.75 \mathrm{a}$ \\
P4 (80 ml/Itr air) & $4.50 . \mathrm{a}$ & $5.63 \mathrm{a}$ & $7.25 \mathrm{a}$ & $9.13 \mathrm{a}$ & $11.25 \mathrm{a}$ & $12.25 \mathrm{a}$ \\
\hline
\end{tabular}

Keterangan : Angka rata-rata yang diikuti oleh huruf yang sama tidak berbeda nyata menurut Uji BNT taraf nyata $5 \%$

Tabel 3 menunjukkan bahwa perlakuan konsentrasi POC tauge dari berbagai konsentrasi memberikan jumlah daun yang sama. Hal ini disebabkan kandungan $\mathrm{N}$ yang terdapat dalam $\mathrm{POC}$ tauge sebesar $0,08 \%$, belum mampu mensuplai unsur hara untuk pembentukan daun tanaman kailan. Unsur $\mathrm{N}$ yang terdapat dalam media tanam berperan dalam pembentukan daun. Nitrogen dapat mempercepat proses fotosintesis sehingga membentuk organ daun menjadi lebih cepat. Unsur $\mathrm{N}$ merupakan unsur penting bagi tanaman [13].

\section{Panjang Akar}

Jumlah panjang akar tanaman Kailan diukur sebanyak 1 kali yaitu pada umur 49 Hst. Berdasarkan analisis sidik ragam menunjukan bahwa perlakuan konsentrasi POC tauge tidak berpengaruh nyata terhadap panjang akar kalian pada semua umur pengamatan. Rata-rata panjang akar tanaman kalian dapat dilihat pada Tabel 4.

Tabel 4. Pengaruh Perlakuan Terhadap Panjang Akar Tanaman Kailan

\begin{tabular}{lc}
\hline Perlakuan & Rata-rata Panjang akar $(\mathrm{cm})$ \\
\hline P0 (0 ml/ltr air) & $8,75 \mathrm{a}$ \\
P1 (20 l/Itr air) & $9,00 \mathrm{a}$ \\
P2 (40 ml/ltr air) & $9,88 \mathrm{a}$ \\
P3 (60 ml/ltr air) & $11,25 \mathrm{a}$ \\
P4 (80 ml/ltr air) & $9,50 \mathrm{a}$
\end{tabular}

Keterangan : Angka rata-rata yang diikuti oleh huruf yang sama tidak berbeda nyata menurut Uji BNT taraf nyata $5 \%$ 
Pada Tabel 4, terlihat bahwa panjang akar tanaman kalian terbesar dari pemberian konsentrasi POC tauge $60 \mathrm{ml} /$ liter, walaupun tidak berbeda dengan yang lain. Peranan unsur hara yang tersedia dalam keadaan optimum saling mendukung satu dengan yang lainya dalam proses fotosintesis, Tersedianya unsur $\mathrm{K}$ yang optimum, menyebabkan tanaman dapat menghasilkan akar yang besar sehingga mampu menyerap unsur-unsur yang dibutuhkan tanaman. Pemberian pupuk organik cair mendorong akar tanaman bisa tumbuh dengan sempurna karena pupuk cair diperkaya dengan unsur-unsur mikro seperti nitrogen, kalium, sulfur kalsium, dan magnesium [11].

\section{Bobot Basah}

Bobot basah tanaman Kailan diukur sebanyak 1 kali yaitu pada waktu panen umur 49 Hst. Berdasarkan analisis sidik ragam menunjukan bahwa perlakuan konsentrasi POC tauge berpengaruh nyata terhadap bobot basah tanaman kalian. Ratarata bobot basah tanaman kalian dapat dilihat pada Tabel 5 .

Tabel 5. Pengaruh Perlakuan Terhadap Bobot basah Tanaman Kailan

\begin{tabular}{lc}
\hline Perlakuan & Rata-rata Bobot Basah (gr) \\
\hline P0 (0 ml//tr air) & $80.50 \mathrm{a}$ \\
P1 (20 ml/Itr air) & $61.00 \mathrm{a}$ \\
P2 (40 ml/ltr air) & $81.00 \mathrm{a}$ \\
P3 (60 ml/ltr air) & $110.13 \mathrm{~b}$ \\
P4 (80 ml/ltr air) & $83.13 \mathrm{a}$ \\
\hline
\end{tabular}

Keterangan : Angka rata-rata yang diikuti oleh huruf yang sama tidak berbeda nyata menurut Uji BNT taraf nyata $5 \%$

Tabel 5 menunjukkan bahwa tidak ada tambahan unsur hara yang perlakuan konsentrasi POC tauge $60 \mathrm{ml} /$ liter terdapat dalam POC Tauge. Pertumbuhan memberikan bobot basah tanaman kalian tanaman Kailan menjadi terhambat karena terbesar (110,13 gr) dibandingkan dengan tanaman tidak tercukupi unsur hara, makro konsentrasi POC tauge $0 \mathrm{ml} /$ liter, $20 \mathrm{ml} /$ liter, $40 \mathrm{ml} /$ liter dan $80 \mathrm{ml} /$ liter. Bobot basah terendah diperoleh pada konsentrasi POC tauge $0 \mathrm{ml} /$ liter. Hal ini disebabkan maupun unsur hara mikro. Pemberian POC tauge menyebabkan tanah menjadi gembur sehingga penyerapan unsur hara menjadi optimal. Ketersedian unsur hara pada 
tanaman merupakan salah satu faktor lingkungan yang sangat menentukan laju pertumbuhan pada tanaman, sebagian besar bobot basah tanaman disebabkan banyaknya kandungan air yang terdapat pada tanaman.

Berat basah ekonomis suatu tanaman menyatakan komposisi hara dalam jaringan tanaman dengan mengikutsertakan kandungan air, di mana $70 \%$ dari berat basah tanaman hidup terdiri dari air sebagai penyusunnya dan penambahan berat tanaman dipengaruhi oleh bentuk fisik dari tanah atau media tumbuh yang mendukung, semakin baik tekstur dan strukturnya maka tanaman akan mudah menyerap hara serta pemanfaatan hara tanaman untuk pertumbuhan dan perkembangan tanaman berjalan dengan optimal [10].

\section{KESIMPULAN}

Pemberian POC tauge tidak berpengaruh terhadap tinggi tanaman, jumlah daun, panjang daun, dan panjang akar tanaman kalian. Pemberian POC tauge berpengaruh terhadap bobot basah tanaman kalian. Perlakuan konsentrasi POC tauge $60 \mathrm{ml} /$ liter merupakan konsentrasi yang tepat untuk diaplikasikan pada tanaman kailan.

\section{DAFTAR PUSTAKA}

Agus, S. 2010. Studi Deskriptif Effect Size
Penelitian-Penelitian Di Fakultas

Psikologi Universitas Sanata Dharma. Jurnal Penelitian. 14(1): 1-17.

Arifiani, N, Sani, T.A., dan Utami, A.S. 2015. Peningkatan Kualitas Nata De Cane dari Limbah Nira Tebu Metode Budchips dengan Penambahan Ekstrak Tauge sebagai Sumber Nitrogen. Bioteknologi, 12: 29-33.

Duaja, W. 2012. Pengaruh Pupuk Urea, Pupuk Organik Padatan dan Cair Kotoran Ayam terhadap Sifat Tanah, Pertumbuhan, dan Hasil Selada Keriting (Lactuca sativa L.) Di Tanah Inceptisol. Agriculture, 1 (4): 12-22.

H. Heryadi, R. Noviyanti, dan Nurhasanah. 2010. Potensi Pemanfaatan Limbah Udang dan Ekstrak Fitohormon dalam Meningkatkan Pertumbuhan Tanaman Cabai dan Bayam. Laporan Hasil Penelitian yang Dipublikasikan. Universitas Terbuka.

Jamilah dan Nuryulsen, S. 2012. Pengaruh Dosis Urea, Arang Aktif, dan Zeolit Terhadap Pertumbuhan dan Hasil Padi Sawah (Oryza sativa). Jurnal Agrista, 6 (3).

Hadisuwito, S. 2012. "Membuat Pupuk Cair". PT. Argo Media Pustaka. Jakarta.

Listiana, A. 2016. Analisis Faktor-Faktor yang Berhubungan dengan Kejadian Anemia Gizi Besi pada Remaja Putri Di SMKN 1 Terbanggi Besar Lampung Tengah. Jurnal Kesehatan. 7(3): 455-469. 
N. Trisna, H. Umar, dan Irmasari. 2013. Pengaruh Berbagai Jenis Zat Pengatur Tumbuh terhadap Pertumbuhan Stump Jati (Tectona grandis)", Warta Rimba, 1(1): 1-9.

Nurhasanah. 2017. Analisis Potensi Hasil Fermentasi Tauge sebagai Pupuk Cair Seminar Nasional Riset Inovatif 2017ISBN: 978-602-6428-11-0. Hal. 768-773.

Parnata, A. 2010. Meningkatkan Hasil Panen Dengan Pupuk Organik. Agromedia Pustaka. Cet. I . Jakarta.

Rabumi, W. 2012. Pengaruh Pemberian Pupuk Nitrophoska Elite dan Limbah Lidah Buaya Terhadap Pertumbuhan dan Hasil Tanaman Lobak pada Tanah
Alluvial di Polybag. Fakultas Pertanian Universitas Panca Bakti. Pontianak.

Rahmat, P. 2015. Bertanam Hidroponik Gak Pake Masalah. Jakarta ; Agromedia Pustaka.

Samadi, B. 2013. Budidaya Intensif Kailan Secara Organik dan Anorganik. Jakarta: Pustaka Mina.

Sinaga, P. Meiriani., dan Hasana, Y. 2014 dalam Gordianus Amuro, Luluk Syahr Banu dan Siti M. Sholihah. Aplikasi Dosis Pupuk Cair Limbah Lidah Buaya terhadap Pertumbuhan dan Produksi Kailan. Jurnal Ilmiah Respati Vol 9, No 2 (2018). e-ISSN : 2622-9471, p-ISS : 1411-7126. 